\title{
Assessing the Impact of Ho Chi Minh City Dieu Phap Pagoda's Spiritual Support Activities on the Change in Lifestyle, Behavior of Buddhists and Visitors
}

\author{
Huynh Van Son \\ Ho Chi Minh City University of Education, Ho Chi Minh City, Vietnam
}

\begin{abstract}
All of the spiritual support activities impact on lifestyle, behavior of Buddhists and visitors at "pretty positive" level (GPA from 3.61 to 4.25). Five activities impacting the most are "affection shelter", "prayer", "mid-autum festival", and Sen Hong Buddihist family.

Keywords: assessing the impact, spiritual support activities, change in lifestyle, change in behavior, Buddhist, visitor
\end{abstract}

\section{Introduction}

In psychology, cognition-attitude-behavior is the structure or the way of human awareness. In Buddhism, this way is started from cognition, then gone to peacefulness or positive attitude and expressed by lifestyle and behavior. At the end, Buddhism leads people to a good life with thinking good and doing good. Therefore, Buddhism organizes many spiritual support activities in order to make that purpose come true better (Huynh, 2013).

Ho Chi Minh city Dieu Phap pagoda is a religious establishment under Buddhist Church of Ho Chi Minh City, which was founded in 1964, located at 88 Trang Long Street, Ward 13, Binh Thanh District by Venerable Thich Nguyen Phap abbot. At Dieu Phap pagoda, activities within the scope of religion as well as social, charitable activities attract more and more participants who are not only in Ho Chi Minh City but also in other provinces. It can be said that Dieu Phap pagoda is a spiritual support place for a large segment of residents. Therefore, understanding the impact of Dieu Phap pagoda's spiritual support activities on the change in lifestyle, behavior of Buddhists and visitors has had a practical significance in order to get a more comprehensive view in assessment.

\section{Method}

To find out the change in lifestyle, behavior of Buddhists and visitors, the questionnaire was designed according to five selected questions from the lowest to the highest, the lowest score is 1 and the highest is 5 , the GPA of each question is calculated as follows:

(1) From 1 to 1.5: Very low;

(2) From 1.51 to 2.5: Low;

Huynh Van Son, Ph.D., associate professor, Department of Psychology-Education, Ho Chi Minh City University of Education. 
(3) From 2.51 to 3.5: Average;

(4) From 3.51 to 4.5: Pretty;

(5) From 4.51 to 5: Good.

\section{Participants}

The study surveyed over 471 people, including 111 men (23.6\%) and 360 women (76.4\%). Thus, women account for three quarters of all. This is also reflected in the fact beause women go to the pagoda more often than men. In terms of jobs, there are 122 students - higher students (25.9\%), 140 officials (29.7\%), 42 traders (8.9\%), 69 homemakers (14.6\%), and 98 freedom workers (20.8\%). Thus, the occupation of the objects is the quite diverse and relatively even in the proportion. The study of the impact of Dieu Phap pagoda's spiritual support activities on the change in lifestyle, behavior of Buddhists and visitors pays attention to pagoda's activities that are conducted regularly. Besides, assessment also considers the researching aspect of this topic and self-assessment of pagoda.

\section{Research Results}

\section{Assessing the Impact of Ho Chi Minh City Dieu Phap Pagoda's Spiritual Support Activities on the Change in Lifestyle, Behavior of Buddhists and Visitors}

All of the spiritual support activities impact on lifestyle, behavior of Buddhists and visitors at "pretty positive" level (GPA from 3.61 to 4.25). Five activities impacting the most are "affection shelter", "prayer", "mid-autum festival", and Sen Hong Buddihist family with the GPAs are 4.28, 4.25, 4.21, 4.18, 4.13, respectively.

Regarding "affection shelter" activites, almost Buddhists and visitors have said that after visiting, chatting with elderly people or children there, they were treated better to their parents, lived with more love. From the real story of elderly people at a nursing home, Buddhists and visitors have a chance to review their acts, their behaviors that make them adjust and improve themselves.

While "praying", besides the spiritual values that Buddhists and visitors receive, the impact on acts and behavior also appear. For Buddhists and visitors who really understand Buddhism will be aware that the Buddhist scriptures system just directs others, the deciding factor is each person receives it. The important factor is to practice Buddhism in life to be able to harvest the "sweetie fruit".

"Mid-Autumn Festival" is dedicated to children. However, the organization of the Mid-Autumn festival is not only the participation of the children but also adults as preparation, logistics, and organization. A visitor shared that: "Every autumn occasion, I found myself more accountable. I understand that the children feeling and especially, I was trying to be able to care for children".

"Sen Hong Buddhist family" is a very exciting activity, bearing the "psychological color" of Dieu Phap pagoda. The depth interviews showed that most of the children after participating in this activity are the positive changes in cognition and skills. Thus, changes in objects's behavior are quite clear and practical. This activity is like a form of group activities or skill-clubs so the change in skills is also understandable.

"Accommodate and benefit all living beings", "obsequies", "free clinic" are low-impact activities to change Buddhists and visitors's lifestyle and behavior when compared with other activities of Dieu Phap pagoda. However, comment on GPA, the levels of impact of these activities are still in the "pretty positive". Because these are less organized activities at Dieu Phap pagoda, Buddhist and visitors have fewer opportunities to participate. Therefore, the impact of these activities on the behavior, lifestyle and behavior of Buddhists and 
visitors is not strong when compared with other activities.

Thus, the impact of Dieu Phap pagoda's activities on lifestyle, behavior of objects is in the "pretty positive" level. This is positive sign for Dieu Phap pagoda because this result demonstrates that the activities of pagoda are really valuable. In other words, Dieu Phap pagoda really goes into social life and affects the operation of a majority of people in the Vietnamese community.

Table 1

Assessing the Impact of Ho Chi Minh City Dieu Phap Pagoda's Spiritual Support Activities on the Change in Lifestyle, Behavior of Buddhists and Visitors

\begin{tabular}{llllc}
\hline Serial number & Activities & GPA & Standard deviation & Ranking \\
\hline 1 & Prayer & 4.25 & 0.90 & 2 \\
2 & Chanting & 4.13 & 0.70 & 5 \\
3 & Repentance & 4.08 & 0.82 & 7 \\
4 & Meditation & 4.04 & 0.72 & 9 \\
5 & Release of animals & 4.06 & 0.77 & 8 \\
6 & Posadha & 3.87 & 0.89 & 13 \\
7 & Taking refuge & 4.08 & 0.75 & 7 \\
8 & The night festival of flower garlands and colored lanterns & 4.10 & 0.74 & 6 \\
9 & Pilgrimage in 10 pagoda's scenery & 3.95 & 0.84 & 12 \\
10 & Accommodate and benefit all living beings & 3.58 & 0.77 & 17 \\
11 & Obsequies & 3.61 & 0.83 & 16 \\
12 & Requiem in large scale & 3.87 & 0.79 & 13 \\
13 & Affection shelter & 4.28 & 0.70 & 1 \\
14 & Sen Hong Buddhist family & 4.18 & 0.85 & 4 \\
15 & Eating house for the poor & 4.10 & 0.83 & 6 \\
16 & Free clinic & 3.81 & 0.86 & 15 \\
17 & Giving gifts to the poor & 4.01 & 0.91 & 10 \\
18 & Entrance Exam Support Program & 3.96 & 0.94 & 11 \\
19 & Relief & 3.84 & 0.93 & 3 \\
20 & Mid-Autumn festival & 4.21 & 0.82 & 14
\end{tabular}

Comparison of the Difference in Assessing the Impact of Ho Chi Minh City Dieu Phap Pagoda's Spiritual Support Activities on the Change in Lifestyle, Behavior of Buddhists and Visitors on Some Aspects

Comparison of the difference in assessing the impact of Ho Chi Minh city Dieu Phap pagoda's spiritual support activities on the change in lifestyle, behavior of Buddhists and visitorson gender and status (Buddhists-visitors) aspects by independent sample $t$-test shows no significant difference statistically. Thus, although there are differences in GPA between male and female objects (GPAs are 4.05 and 3.82); between Buddhists and visitors (GPAs are 4.02 and 3.88), this difference was not significant in statistics. This demonstrates that Dieu Phap pagoda's activities affect lifestyle, behavior of both male and female gender, both Buddhists and visitors. Statistical results are plotted in Figure 1.

One-way ANOVA test is conducted to compare the difference in assessing the impact of Ho Chi Minh city Dieu Phap pagoda's spiritual support activities on the change in lifestyle, behavior of Buddhists and visitors on family circumstances, economic conditions, family and spiritual life aspects show no significant difference statistically. 
Thus, a change in lifestyle, behavior of those who have no family or family who have prosperous economic conditions or difficult economic conditions, who have happy mental life or unhappy mental life after participating in activities is not significant statistically.

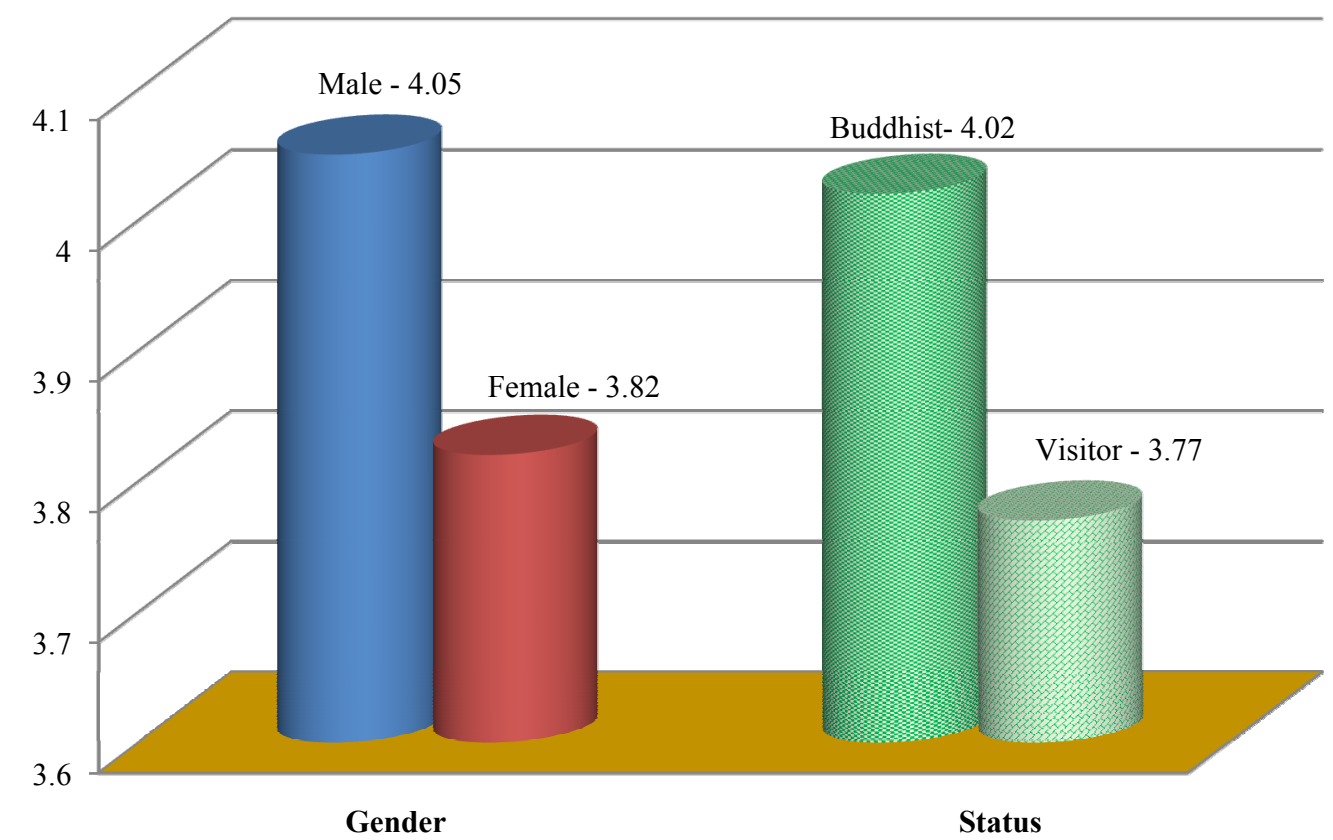

Figure 1. Comparison of the difference in assessing the impact of Ho Chi Minh city Dieu Phap pagoda's spiritual support activities on the change in lifestyle, behavior of Buddhists and visitors on gender and status (Buddhists-visitors) aspects.

The result of one-way ANOVA test showed that the difference was statistically significant in age group of the change in objects's lifestyle, behavior (Sig. $=0.00$ ). Observing Figure 2 shows that lifestyle, behavior of $\geq$ 51 year-old group has the most change $(\mathrm{GPA}=4.33)$, the second one is 21-30 year-old group $(\mathrm{GPA}=4.07)$, the third one is 41-50 year-old group (GPA $=3.9$ ), the fourth one is $\leq 20$ year-old group (GPA $=3.75)$, and the last one is $31-40$ year-old group $(\mathrm{GPA}=3.23)$.

Thus, the oldest group (51 and older) is the group with most changes in lifestyle, behavior after participating in activities of Dieu Phap pagoda. Maybe, in this age, people have basically stable in family, career and the important thing is that they have had many experiences, so they easily absorb the values of Buddhism in order to apply in real life.

One-way ANOVA test is conducted to compare the difference in assessing the impact of Ho Chi Minh city Dieu Phap pagoda's spiritual support activities on the change in lifestyle, behavior of Buddhists and visitors of occupational aspects. Result shows significant differences $(\mathrm{Sig} .=0.00)$ and this difference is shown in Figure 3.

Among occupational groups, homemaker group $(\mathrm{GPA}=4.72)$ has most changes, the second is the trader group (GPA = 4.38), the third is worker and employee group (GPA = 4.1), the fourth is student group (GPA = $3.75)$, and finally one is freelance worker group $(\mathrm{GPA}=3.64)$. This phenomenon is caused by the fact that homemakers have more free time to go to pagoda than other occupational groups, so they have the conditions to participate in the activities of pagoda and receive more value. As a result, they have change, tune in daily life according to his/her own assessment. 


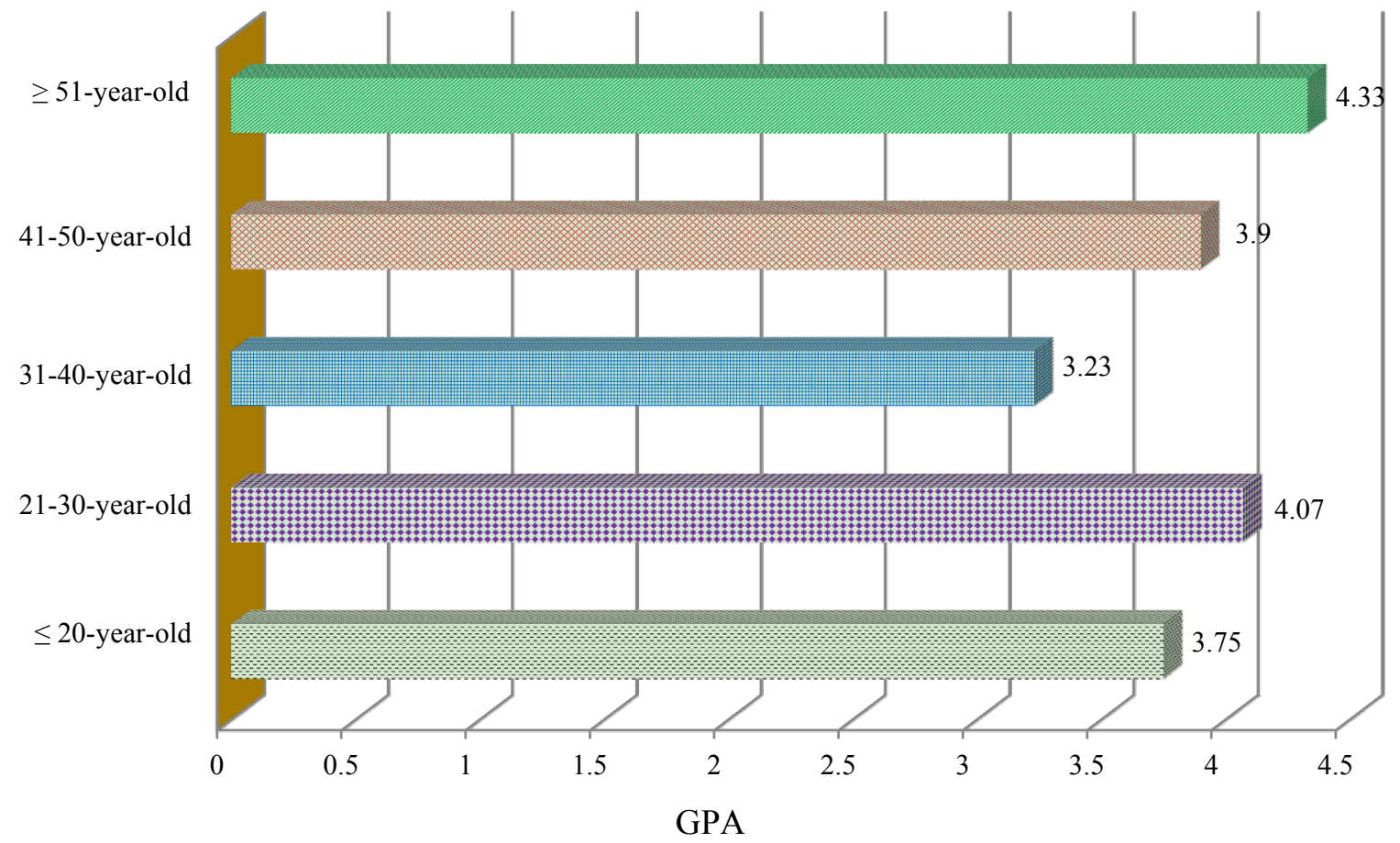

Figure 2. Comparison of the difference in assessing the impact of Ho Chi Minh city Dieu Phap pagoda's spiritual support activities on the change in lifestyle, behavior of Buddhists and visitors on age group aspects.

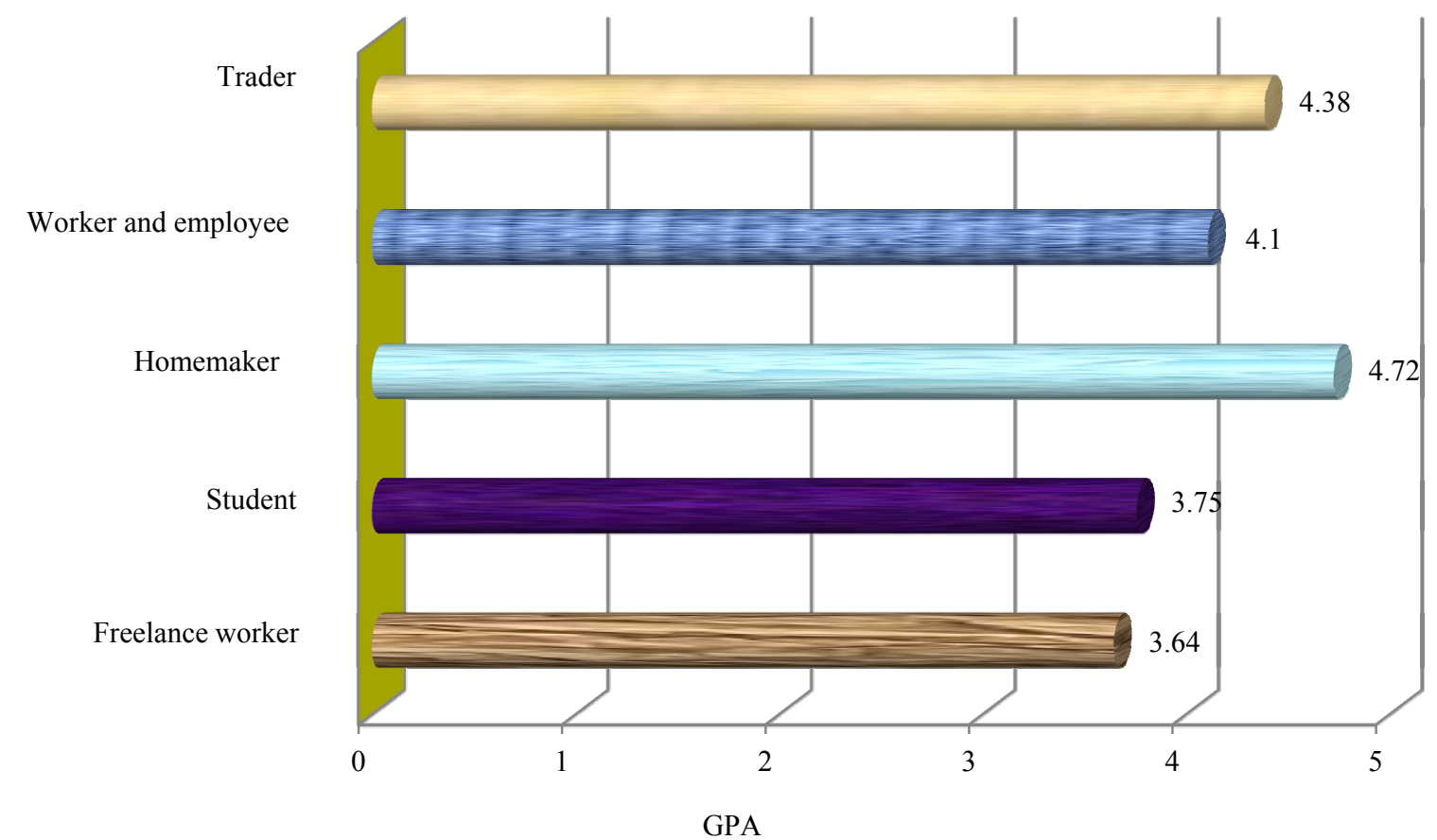

Figure 3. Comparison of the difference in assessing the impact of Ho Chi Minh city Dieu Phap pagoda's spiritual support activities on the change in lifestyle, behavior of Buddhists and visitors on occupational aspects. 


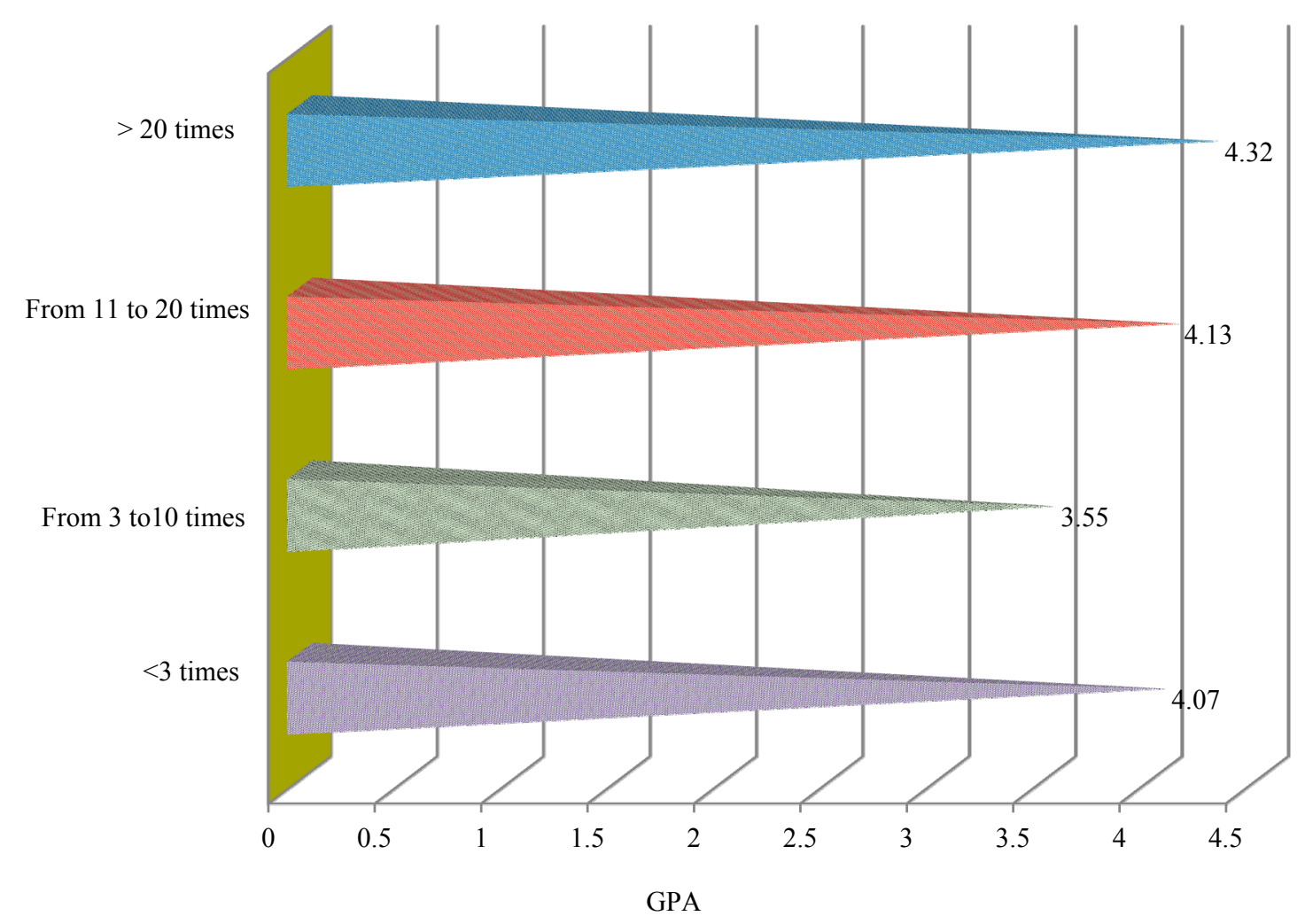

Figure 4. Comparison of the difference in assessing the impact of Ho Chi Minh city Dieu Phap pagoda's spiritual support activities on the change in lifestyle, behavior of Buddhists and visitors on go-to-pagoda frequencies aspects.

For traders group, because of particular occupations, these people tend to look to the spiritual world. Therefore, they receive more value for better and more compassionate life.

An interesting result when conducting ANOVA test to compare the difference of go-to-pagoda frequencies a year in changing level lifestyle, behavior after participating in Dieu Phap pagoda's activities: The result shows that the number of times each year going to pagoda is not always proportional to the change in lifestyle, behavior of objects.

Observing Figure 4, the groups of objects who just go to pagoda under three times a year change in lifestyle, behavior more positively than the group of objects who go to pagoda from three to 10 times (GPA is 4.07 compared with 3.55 ). Thus, there are those who do not often go to pagoda but they access to and understand the meaning of Buddhism so that self-adjust their own lifestyles. This result suggests one more approach for Dieu Phap pagoda, that is the approach of out reach. In other words, the propagation of Buddhism is not only limited to close Buddhists and visitors but also Buddhists and visitors who rarely go to pagoda.

\section{Conclusion and Recommendation}

All of the spiritual support activities impact on lifestyle, behavior of Buddhists and visitors at "pretty positive" level (GPA from 3.61 to 4.25). Five activities impacting the most are "affection shelter", "prayer", "mid-autum festival", and Sen Hong Buddihist family. Building pagoda as a spiritual support point for a segment of the population is understood as a series of actions in order to guide and help people live better. This 
is a process which requires an investment of ideas, content, forms and related conditions such as physical condition, time, etc..

The construction of the pagoda as spiritual support point has to be based on the positive impact on the cognition, attitude, and behavior of the people who live pagoda or even visit pagoda:

Firstly, determining spiritual support objects that pagoda proactively undertakes (in the spirit of the pagoda welcomes any object or group of objects);

Secondly, attenting to conditions such as physical facilities (infrastructure conditions and financial), human resources, activities's content in order to supports people's spirit effectively;

Thirdly, attenting to the needs of people who need support, the general direction of social life, the development of pagoda (Huynh, 2013).

These measures are divided into general measures and specific measures for each activities in order to continue to build the spiritual support point sustainability.

\section{Reference}

Huynh, V. S. (2013). Current status of the construction of Dieu Phap Pagoda as spiritual support point for a segments of the population HCMC and neighboring provinces. Chi Minh City University of Pedagogy.

Nguyen, T. N. (1997). The influence of ideology and religion for people of Vietnam today. The National Political Publishing House.

Santina, P. D.(1996). The foundation of Buddhism. Social Sciences Publishing House.

Staihe, T. (1992). The concept of "the absolute spirit" in Heghen's philosophy. EOS Green Otilien Publishing House.

Thich, T. T. (1998). Buddhist psychology. Ho Chi Minh City Publishing House.

Venerable, K. Sri Dhammananada. (1994). (Translated by Bhikkhu Thich Quang Tam). Buddhist in the eyes of intellectuals, the Buddha not only aware of the fact that the Supreme, he express his great knowledge, greater than knowledge of "The Spirit". Hanoi Publishing House.

Vi, Q. T. (1998). Spiritual life of the individual-The concept and principles of research. Social Sciences Publishing House.

$\mathrm{Vu}$, K. Q. (2002). Religion and modern life. Hanoi: The Center for Social Sciences and Humanities.

Vu, D. (1998). Psychology of religion. Hanoi Publishing House. 